\title{
Marcadores Identitários do professor de Biologia de Timor-Leste: um estudo a partir de uma experiência de cooperação internacional
}

\author{
Marina Pereira Reis ${ }^{*}$ \\ Verónica Marcela Guridi** \\ Elisabeth Barolli*** $^{* *}$
}

\section{Resumo}

A convivência e o trabalho na Missão de Cooperação entre Brasil e Timor-Leste (BRASIL, 2012), no período de 2007 a 2009, foram as razões para este estudo sobre a constituição da identidade docente do professor de Biologia desse país e sua estreita relação com o contexto político, histórico, social e cultural do território timorense. Este trabalho objetivou investigar os marcadores identitários do professor leste-timorense declaradamente presentes naquele período e que, possivelmente, tenham condicionado a construção da identidade profissional desses docentes de Biologia. A pesquisa procurou responder perguntas do tipo: Como tem se dado a (re)construção da identidade profissional dos seus docentes que ensinam Biologia? Ou, ainda, quais marcadores identitários incidem na configuração dessas identidades? Sendo assim, o estudo esteve fundamentado teoricamente nas conceituações de Claude Dubar a respeito da constituição das identidades. A metodologia utilizada ancorou-se na pesquisa bibliográfica e documental, por meio da interpretação e análise de registros documentais e memoriais coletados durante a formação realizada em um projeto de cooperação internacional. Na análise dos dados foi possível observar que os marcadores identitários desses professores evidenciam influências advindas da sua recente história de dominação e liberdade, sobrevivência e resistência.

Palavras-chave: Identidade Profissional. Timor-Leste. Formação de Professores em Serviço.

\footnotetext{
* Mestre em Ensino de Ciências pela Universidade de São Paulo (USP). Coordenadora Pedagógica e formadora de professores na Secretaria Municipal de Educação de São Vicente, SP.

* Doutora em Educação pela Universidade de São Paulo (USP). Professora da Escola de Artes, Ciências e Humanidades da Universidade de São Paulo (USP).

*** Doutora em Educação pela Universidade de São Paulo (USP). Professora da Universidade Estadual de Campinas (UNICAMP).
} 


\section{Introdução}

O trabalho realizado no período de 2007 a 2009 no âmbito de uma Missão de Cooperação entre Timor-Leste e o Brasil motivou este estudo sobre a constituição da identidade docente do professor timorense de Biologia. Nesses dois anos em que uma das autoras conviveu com a sociedade timorense, aliando sua experiência profissional e pessoal às ações de cunho educacional realizadas naquela ocasião, foi possível entrar em contato com uma cultura singular e fortemente marcada por uma história de dominação.

Mais especificamente, o estudo investiu esforços na investigação de marcadores identitários de cidadãos leste-timorenses que participaram da Missão de Cooperação Educacional e que vinham exercendo a profissão docente na área de Biologia. Inegavelmente, o percurso desses sujeitos sociais, suas histórias de vida e resistência são construtos da sua identidade enquanto cidadãos e profissionais. Dessa forma, o estudo visou responder às seguintes perguntas: Como, diante do cenário timorense, tem se dado a (re)construção da identidade profissional dos seus docentes que ensinam Biologia? Ou, ainda, quais marcadores identitários incidem na configuração dessas identidades?

Espera-se que os resultados deste estudo tornem possível um novo olhar sobre a formação, tanto inicial quanto continuada, desse profissional. Assim, novas oportunidades de desenvolvimento profissional poderão ser propostas e oferecidas, notadamente em Ciência e Tecnologia, por se revestirem de grande importância num país com essa realidade.

Como veremos, a história de Timor-Leste, fortemente marcada por períodos históricos bem delimitados, cujas especificidades ofereceram elementos de naturezas muito diversas, inclusive contraditórios, impregnaram de muitos significados a vida e a identidade do povo timorense. Sem dúvida, a articulação ou mesmo o sincretismo entre as características históricas, culturais e linguísticas dos diferentes períodos, somadas à particular divisão geográfica do país, oferecem um panorama singular e, ao mesmo tempo, complexo dessa história. As bruscas mudanças e rupturas sociopolíticas ocorridas na sociedade leste-timorense, considerando os diferentes períodos que abrangem desde o domínio português até os tempos atuais, imprimiram características peculiares na formação identitária de todos os cidadãos desse país, o que inclui certamente os professores. Com os devidos aportes teóricos, ancorados na obra de Claude Dubar (2005), o trabalho procura explicitar marcadores identitários que incidem na configuração das identidades desses sujeitos, que haviam escolhido para sua atuação profissional o ensino de Biologia. 


\section{À guisa de um breve histórico}

Timor-Leste foi efetivamente colonizado por Portugal em meados do século XIX, relativamente ao regime anterior fundado em alianças simbólicas. Em novembro de 1975, Timor declarou sua independência, mas, em dezembro desse mesmo ano, foi invadido e ocupado pela Indonésia de forma não pacífica. A partir de então, o povo de Timor se viu sob o domínio da Indonésia e privado de sua liberdade, sua língua e sua cultura. Sentindo-se profundamente desrespeitada pela truculência indonésia, boa parte da população fugiu e passou a viver nas montanhas juntamente com as forças de resistência. A fuga para as montanhas, apesar de arriscada e perigosa, foi, para muitos timorenses e suas famílias, a melhor ou única opção para salvarem suas vidas e conservarem sua liberdade. Essa opção significou abandonarem suas casas e seus bens, bem como familiares e amigos que não teriam condições de sobrevivência na mata. Nesse período, que, para alguns, durou meses e para outros tantos foram anos, os refugiados receberam proteção das Forças Armadas da Libertação Nacional de TimorLeste (Falintil) e ajuda da Igreja Católica e de timorenses que se mantiveram nas cidades.

Em 1999, após um ato de autodeterminação patrocinado pelas Nações Unidas, o governo indonésio deixou o controle do território, e Timor-Leste tornou-se o primeiro novo Estado soberano do século XXI, em 20 de maio de 2002. Após a independência, o país tornou-se membro das Nações Unidas e da Comunidade dos Países de Língua Portuguesa (CPLP).

A retirada das tropas indonésias, mais uma vez, deixou um rastro de destruição e morte. Praticamente toda a infraestrutura do país foi destruída, como abastecimento de água estradas e vias públicas, telefonia, quase toda a rede elétrica, escolas, prédios públicos, casas, etc. Segundo Gertil (2002, p. 40), "calcula-se que entre as vítimas da guerra e as da fome tenham perecido cerca de 150.000 pessoas, ou seja, um quarto da população timorense, que segundo o censo de 1970 era de 610.000 habitantes".

Assim, desde sua independência o país está em reconstrução. Seus prédios públicos e particulares, residências e a infraestrutura de modo geral têm sido recuperados, porém a árdua tarefa vai além da sua estrutura física. No caso específico da educação muito se tem feito, mas ainda há muito o que fazer.

Ainda em 1999, logo após o término do domínio da Indonésia e dos distúrbios e saques promovidos pelas milícias pró-Indonésia, o governo brasileiro, por meio da Agência Brasileira de 
Cooperação $(\mathrm{ABC})$, marcou presença no novo país na perspectiva de apoiar e contribuir para sua reconstrução. Por meio de um Protocolo de Cooperação Técnica entre o governo brasileiro e a Administração Transitória das Nações Unidas em Timor-Leste, o Brasil passou a cooperar no esforço de reestruturação em algumas áreas então consideradas prioritárias: educação, agricultura e formação profissional (BRASIL, 2000). Na área da educação, particularmente no que se refere à formação de professores, ficou acordado que a cooperação seria realizada nas diversas áreas do conhecimento e nos diferentes níveis de ensino, como forma de resgatar e difundir a Língua Portuguesa, bem como permitir que esses profissionais a utilizem no ensino das crianças e dos jovens timorenses.

Em 2002, depois de oficialmente declarada a independência de Timor-Leste, o idioma português tornou-se a língua oficial do país, juntamente com o Tétum, que é a língua nacional e cooficial. No processo de reintrodução da Língua Portuguesa tiveram início os programas de cooperação apoiados pela Coordenação de Aperfeiçoamento de Pessoal de Nível Superior (Capes), que têm permitido a participação de professores brasileiros como cooperantes na área de educação.

A Cooperação Educacional Brasileira atua em Timor-Leste desde 2005 e, atualmente, é organizada pelo Programa de Qualificação de Docente e Ensino da Língua Portuguesa (PQLP), instituído pelo Decreto $\mathrm{n}^{\mathrm{o}} 5.274$ de 18 de novembro de 2004 (BRASIL, 2004). No período compreendido entre o segundo semestre de 2007 e o primeiro de 2009, esse programa viabilizou um projeto em que professores brasileiros se responsabilizaram pela implementação de uma formação continuada a fim de proporcionar aos professores timorenses acesso à materiais didáticos em português (apostilas e guia do professor), naquela época insuficientes ou inexistentes no país. Essa medida procurou viabilizar o cumprimento à legislação para adoção da Língua Portuguesa como língua de instrução. Além disso, foram realizadas capacitações dos professores para a utilização desses novos materiais didáticos. Coube à equipe de formadores a desafiadora tarefa de planejar e implementar cursos de formação de professores nas mais diversas áreas do conhecimento que previam atendimento aos termos da cooperação entre os dois países, o respeito ao currículo local e o alcance dos objetivos estabelecidos pelo projeto. Projetou-se, ainda, acompanhamento pedagógico e aprofundamento de conteúdos curriculares com vistas à melhoria da qualidade de ensino.

Com a chegada do grupo de formadores brasileiros, foram organizadas as classes de professores timorenses por área do conhecimento, a saber: Matemática, Química, Física, Biologia, História e Geografia; que ficaram alojados no Instituto Nacional de Formação Profissional e Contínua (INFPC) atualmente Instituto de Formação de Docentes e Profissionais de Educação (Infordep), na capital Díli, 
pelo período do curso. As aulas eram ministradas por aproximadamente três meses, pela manhã e à tarde, de segunda-feira a sábado. Concomitante às aulas do Bacharelato, os cooperantes brasileiros, reunidos por área de formação, desenvolveram material didático em Língua Portuguesa para o professor e o aluno timorenses.

Entre os meses de agosto a dezembro de 2007, foram oferecidas as disciplinas de Biologia Geral, Metodologia Específica da Biologia, Técnicas de Laboratório, Ecologia, Microbiologia e aulas práticas desenvolvidas durante as saídas de campo. Já, no semestre seguinte, entre os meses de janeiro e maio de 2008, os participantes receberam aulas de Biologia Geral, Microbiologia e Metodologia para o Ensino da Biologia, além das visitas de campo desenvolvidas aos sábados.

O segundo período aconteceu entre julho de 2008 e junho de 2009. Naquela ocasião, o projeto investiu na produção de material didático de modo que, ao final desse período, o Ministério da Educação (ME/Timor) já possuía livros didáticos em Língua Portuguesa para todo o nível présecundário e secundário, excetuando-se o último ano do secundário, que foi produzido na missão seguinte, entre 2009 e 2010. Além disso, foi implementado naquele período o curso de Capacitação de Docentes para o Ensino de Biologia, Química, Física e Matemática em quatro regiões distintas do país, com pólos nos distritos de Díli, Baucau, Ainaro e Maliana. Foram, ainda, desenvolvidas atividades para o ensino de Biologia em Fatumaca (Baucau).

\section{Os participantes do estudo}

No período da Missão aqui focalizada, entre os anos de 2007 e 2009, o trabalho desenvolvido envolveu os professores timorenses que, naquela ocasião, participaram dos cursos de Formação Continuada em Baucau e Fatumaca, e, em Díli, no Bacharelato de Biologia pelo INFPC, instituição ligada ao ME/Timor e parceira da Universidade Nacional Timor Lorosa'e (UNTL), que conferia regulamentação e certificação aos cursos de formação inicial e continuada de professores. Participaram 155 professores nos cursos de Bacharelato, 46 no curso de Formação Continuada em Fatumaca e 15 em Baucau, todos na área de Biologia. Em Fatumaca e Baucau, alguns dos professores eram os mesmos que já tinham concluído os cursos de Bacharelato realizados na capital, Díli. Assim, do total de professores participantes nas formações de Biologia (216) no período já mencionado, participaram deste estudo 65 docentes, em sua grande maioria professores leigos. 
Uma possível caracterização desses professores, sujeitos da pesquisa, pode ser realizada, inicialmente, de acordo com dois critérios: a faixa etária em que se situavam e a língua que tinham maior fluência, além do Tétum. Há que se recordar que ao longo de sua história o povo timorense ficou às voltas com mudanças na língua oficial.

Assim, um primeiro grupo de professores (Grupo A) era formado por aqueles que antes da ocupação indonésia foram alfabetizados e, alguns deles, deram início a sua atividade laboral, também em Língua Portuguesa. Eram fluentes no idioma. No entanto, durante o domínio indonésio foram proibidos de se comunicar em português. Na ocasião da pesquisa, muitos ainda mantinham um razoável domínio da Língua Portuguesa. Muitos desses professores eram estudantes, durante o período português, nos níveis pré-secundário e secundário quando, devido à invasão indonésia, interromperam seus estudos, que foram retomados anos depois, já em Língua Indonésia, na qual vieram a adquirir fluência.

Outro grupo (grupo B) estava constituído por professores que tiveram o início da alfabetização em Língua Portuguesa (durante o regime colonial), porém após a invasão seguiram seus estudos, muitas vezes ainda na escola primária, no idioma indonésio imposto pelo regime. Assim, adquiriram fluência nesta língua e possuíam pouca ou nenhuma lembrança da Língua Portuguesa. Após a independência, exerciam suas atividades em Tétum ou Indonésio.

Finalmente um terceiro grupo de professores (grupo C) havia dado início aos estudos já sob o regime indonésio, a partir de 1975. Foram alfabetizados em Língua Indonésia, não possuindo praticamente nenhum conhecimento da Língua Portuguesa. Também, após a independência, exerciam a docência em Indonésio (prioritariamente) e Tétum.

A trajetória acadêmica dos professores estava claramente relacionada às suas faixas etárias, sendo que os mais experientes e, portanto, com mais idade, possuíam apenas formação de nível básico ou técnico e, mais recentemente, pré-bacharelato de Língua Portuguesa como etapa inicial ao Bacharelato de Biologia (correspondente à licenciatura curta no Brasil) que viriam a fazer com a cooperação brasileira. Já os mais jovens, com até 10 anos de experiência docente, possuíam, em geral, formação superior pela UNTL ou por outras universidades locais ou da Indonésia. Os professores representados pelo Grupo B também possuíam formação técnica ou de nível básico, porém poucos deles cursaram escolas superiores reconhecidas pelo governo indonésio e outros, assim como aqueles pertencentes ao Grupo A, já haviam cursado o pré-bacharelato de Língua Portuguesa. 
No entanto, a maioria dos representantes do Grupo C já possuía habilitação literária pela UNTL em Biologia, principalmente. Havia poucos que se graduaram em outras universidades ou pela cooperação brasileira no bacharelato de Biologia.

\section{Natureza do estudo e fundamentos metodológicos}

O trabalho metodológico foi estruturado com base em pesquisas de natureza qualitativa, de cunho bibliográfico e descritivo, e pela interpretação e análise de registros documentais.

Foi realizado um levantamento de dados desde os primeiros contatos e convívio com o professor timorense e com o seu país e, obviamente, num contexto mais amplo, com o povo lestetimorense. Essa convivência teve início em julho de 2007 e encerrou-se em março de 2010, apesar desse último período - entre 2009 e 2010 - ter sido dedicado a outros programas internacionais em Timor. Devido ao alcance dos registros, o foco, a qualquer momento, poderia sofrer desvios por se tratar de um tema bastante abrangente e que ainda é carente de estudos mais aprofundados. Em virtude disso, a releitura dos documentos, a análise e as conclusões do estudo perseguiram propósitos bem delimitados que pudessem direcionar à(s) resposta(s) mais adequada(s) aos questionamentos iniciais.

Dessa forma, uma parte da coleta de dados se originou a partir da escrita de relatos solicitados aos professores timorenses como uma das atividades de conclusão do curso de Bacharelato em Biologia. Sem intencionalidade de pesquisa naquele momento, este trabalho adquiriu um caráter muito mais abrangente do que se pretendia na disciplina de Botânica, lecionada naquela ocasião. O objetivo inicial da atividade era a descrição das plantas populares de Timor-Leste que a população refugiada nas montanhas fazia uso para a cura das doenças e dos ferimentos de guerra ou acidentais, para a alimentação dos refugiados etc.

Além desses relatos, e como forma de complementar e dar sustentação aos dados já extraídos dos relatos produzidos no ano de 2007, foi solicitada aos professores a elaboração de um memorial que contasse sobre a experiência escolar por eles vivenciada, as impressões que tinham ou continuavam tendo sobre essas vivências, razões que os levaram a escolher a profissão do magistério, em particular na área de Biociências e, ainda, suas visões sobre a escola, os alunos e sobre os processos de ensino e aprendizagem. Esses memoriais foram produzidos em dois cursos distintos: o de Bacharelato em Díli, 
em 2008, e a formação continuada em Baucau, em 2009, e também serviram como instrumento de avaliação do projeto de Formação Continuada.

Devido à amplitude alcançada pelas produções dos professores, estas foram reunidas e complementadas por outros procedimentos de pesquisa como o estudo da legislação timorense no que se refere à educação e pesquisa bibliográfica de publicações sobre o tema em estudo.

O Quadro 1 apresenta dados quantitativos acerca dos materiais coletados que foram analisados neste estudo.

Quadro 1 - Materiais coletados analisados

Fonte: Elaborados pelos autores.

\begin{tabular}{|c|c|c|}
\hline & Relatos & Memoriais \\
\hline Período de coleta & Maio de 2008 & Fevereiro de 2008 e maio de 2009 \\
\hline Número de exemplares & 32 & 36 \\
\hline
\end{tabular}

\section{Identidade em estudo: uma breve discussão}

Quando se busca caracterizar a identidade de um indivíduo e as formas como se estabelece a sua construção, encontramos uma diversidade de concepções, resultantes de perspectivas particulares às áreas do conhecimento que tratam do tema. No entanto, mesmo sendo um assunto estudado em diferentes domínios com suas respectivas especificidades, no sentido lato, o conceito é definido como uma marca que diferencia as pessoas ou os grupos de pessoas, que os torna similares por suas características, modos de agir e pensar e sua história pessoal. Reforçando essa perspectiva, Chamon (2003) afirma que a noção de identidade, no seu aspecto semântico, é um conceito complexo e, de certa forma, dialético na sua construção, pois:

Trata-se de um lado, do caráter daquilo que é idêntico, isto é, de seres ou objetos perfeitamente semelhantes ainda que distintos e, nesse caso, a identidade é o fato de ser semelhante a outros. Por outro lado, ela é a característica do que é único e assim que se distingue e diferencia totalmente dos outros. (CHAMON, 2003, p. 23).

No campo semântico definido pela autora, identificar significa igualar os indivíduos no sentido de "tornar igual a" e, paradoxalmente, diferenciá-los no sentido de "separar". Dessa forma, identidade remete aos temas da diferença e da alteridade a partir dos traços que caracterizam os indivíduos perante 
os demais, dando-lhes características próprias, tornando-os diferentes uns dos outros e, ao mesmo tempo, mantendo certa similitude enquanto sujeitos em contextos sociais específicos.

Claude Dubar (2005), em especial, baliza este estudo por privilegiar a abordagem sociológica da construção de identidade, entendendo-a como resultado de um processo interno do indivíduo e, também, das interações deste indivíduo durante o seu processo de socialização. Isto é, para ele, apesar de problemática, a identidade "para si” está relacionada à identidade para o outro, pois o indivíduo se reconhece pelo olhar do outro. Seus estudos focalizam como as pessoas e as relações entre elas estabelecidas no processo de construção de identidades sociais e profissionais foram abaladas pelos acontecimentos do último século.

\section{Formas identitárias, marcadores identitários e processos de socialização: os aportes de Dubar e Veiga-Neto}

A ideia de identidade para Dubar (2005) pode ser trabalhada como forma identitária. Ele justifica a sua decisão ao realizar esclarecimentos sobre as formas de identificação e a problemática que elas provocam devido a sua dualidade. Para ele, a explicação dessas "formas de identificação socialmente pertinentes em uma esfera de ação determinada - o que denomino formas identitárias constitui o objetivo da 'abordagem sociológica das identidades"” (DUBAR, 2005, p. XX, grifo nosso). O autor sugere estudar as formas identitárias profissionais a partir de categorias que dialogam com modos de identificação e formas de agir, permitindo observar o que há de individual e compartilhado para caracterizar a identidade profissional, como é o caso da identidade profissional docente.

As diversas formas identitárias que caracterizam os indivíduos podem ser vistas como “combinações” diferentes de marcadores identitários, que são definidos por Veiga Neto (2002, p. 36) como:

[...] os símbolos culturais que funcionam para diferenciar, agrupar, classificar, ordenar e inscrevem-se fundamentalmente no corpo. É sobretudo no corpo que se tornam manifestas as marcas que nos posicionam: ser (ou não ser) baixo, negro, magro, loiro, deficiente. Ter (ou não ter) tal ou qual sexo, idade, língua, etc.; partilhar (ou não partilhar) de tal ou qual costume, tradição, território, classe social, etc. Essas marcas, cujos significados nem são estáveis nem têm a mesma importância ou penetração relativa, combinam-se permanentemente entre si e é principalmente no corpo que se tornam visíveis. 
Os marcadores identitários são fabricados nas ações do cotidiano e produzem certos modos de ser dos indivíduos. Segundo Veiga-Neto (2002), na atualidade existem inúmeros mecanismos e instituições capazes de produzir marcadores ou dar novos contornos aos já existentes, através da ressignificação dos pertencimentos e dos usos que deles se pode fazer. E é discursivamente que os indivíduos se ajustam ou se moldam, criando novos marcadores identitários e mobilizando outros já existentes para, a partir daí, (re)construírem suas identidades. Nessa perspectiva, ao admitir-se a pluralidade de marcadores na construção das identidades, nega-se a fixação das mesmas, o que conduz à compreensão das diferenças.

Para que se entenda de que forma a identidade se estrutura é importante compreender como as variadas relações estabelecidas ao longo da vida, na sua heterogeneidade, evoluem e se articulam aos processos identitários. Para Dubar (2005), é da articulação de dois processos identitários - o relacional e o biográfico - que as identidades se constituem. O Quadro 2 esquematiza as categorias que conduzem à constituição da identidade. Esses processos são aqueles que descrevem as trajetórias objetivas e subjetivas dos indivíduos e são de ordem relacional e biográfica, respectivamente. Na trajetória objetiva, a partir da identificação com instituições julgadas legítimas e por meio de atos de atribuição, configura-se a identidade para outro ou identidade "virtual". Já na trajetória subjetiva, a partir da identificação com categorias julgadas atraentes ou protetoras e por atos de pertencimento, configura-se a identidade para si ou identidade "real". Da articulação desses processos que evoluem para o reconhecimento/não-reconhecimento do que o outro diz do sujeito e para a continuidade/ruptura do que o sujeito diz de si, configuram-se identidades atribuídas e identidades assumidas; identidades herdadas e identidades visadas, nessa ordem.

A identidade é percebida como uma construção social que ocorre em diversos espaços discursivos, como a família, a escola, o trabalho e as organizações de naturezas variadas, dentre outros. Os discursos declarados ou implícitos presentes nesses espaços são como mensagens desencadeadoras da ressignificação das identidades, tendo como pavimento dessa configuração uma pluralidade de marcadores identitários dos indivíduos ou grupos de indivíduos, para além de etnia, gênero, religião ou linguagem. 
Quadro 2 - Categorias de análise da identidade

\begin{tabular}{|c|c|}
\hline Processo relacional & Processo biográfico \\
\hline Identidade para outro & Identidade para si \\
\hline $\begin{array}{c}\text { Atos de atribuição } \\
\text { "Que tipo de homem ou de mulher você é" } \\
=\text { diz-se que você é }\end{array}$ & $\begin{array}{c}\text { Atos de pertencimento } \\
\text { "Que tipo de homem ou de mulher você quer } \\
\text { ser" = você é que diz que é }\end{array}$ \\
\hline $\begin{array}{r}\text { Identidade - numérica (nome atribuído) } \\
\text { - genérica (gênero atribuído) }\end{array}$ & $\begin{array}{l}\text { Identidade predicativa do Eu } \\
\text { (pertencimento reivindicado) }\end{array}$ \\
\hline Identidade social "virtual" & Identidade social "real" \\
\hline $\begin{array}{c}\text { Transação objetiva entre } \\
\text { - identidades atribuídas/propostas } \\
\text { - identidades assumidas/incorporadas }\end{array}$ & $\begin{array}{l}\text { Transação subjetiva entre } \\
\text { - identidades herdadas } \\
\text { - identidades visadas }\end{array}$ \\
\hline $\begin{array}{c}\text { Alternativa entre } \\
\text { - cooperação-reconhecimento } \\
\text { - conflito/não-reconhecimento }\end{array}$ & $\begin{array}{c}\text { Alternativa entre } \\
- \text { continuidades } \rightarrow \text { reprodução } \\
\text { - rupturas } \rightarrow \text { produção }\end{array}$ \\
\hline $\begin{array}{c}\text { "Experiência relacional e social do } \\
\text { PODER" }\end{array}$ & $\begin{array}{c}\text { "Experiência das estratificações, } \\
\text { discriminações e desigualdades sociais" }\end{array}$ \\
\hline $\begin{array}{c}\text { Identificação com instituições julgadas } \\
\text { estruturantes ou legítimas }\end{array}$ & $\begin{array}{c}\text { Identificação com categorias julgadas atraentes } \\
\text { ou protetoras }\end{array}$ \\
\hline
\end{tabular}

Fonte: Dubar, 2005, p. 142.

Nesse sentido, Dubar (2005, p. 105) afirma que "A identidade não é mais do que o resultado simultaneamente estável e provisório, individual e colectivo, subjectivo e objectivo, biográfico e estrutural, dos diversos processos de socialização que, em conjunto, constroem os indivíduos e definem as instituições".

O autor põe de manifesto a sua visão dual sobre as categorias de análise da identidade quando descreve a construção das identidades sociais a partir da articulação entre as duas trajetórias (objetiva e subjetiva), já que a subjetiva depende de interações com o outro, relações essas que configuram a trajetória objetiva.

Essa dualidade é considerada pelo autor como problemática, dado que sempre existem conflitos entre as identificações atribuídas/propostas pelo outro (transação objetiva) e as identificações reivindicadas por si e validadas pelo outro (transação subjetiva). 


\section{Identidade profissional docente}

A construção identitária profissional do professor não escapa às situações de confronto entre a imagem que ele tem de si daquela sinalizada pelos outros com os quais ele se relaciona profissionalmente. Essas situações são descritas por Dubar (2005) como sinais negativos geradores de inseguranças referentes à sua atuação, à desvalorização profissional e à atividade burocrática que realiza em serviço. É, portanto, através desses julgamentos de si e do outro que o profissional se situa no seu próprio ambiente social, adaptando-se e incorporando atitudes pessoais e sociais do outro no convívio profissional.

A identidade profissional do professor que emerge da identidade pessoal e da identidade social deve ser tratada nos campos sociológico e psicológico, visto que ela possui elementos pertencentes a essas duas categorias. Segundo Vianna (1999, p. 71), "a identidade profissional se reveste de significativa importância na relação de pertencimento a uma categoria", como, por exemplo, "nós" professorado, "nós" magistério.

Essa percepção alargada de identidade do sujeito, a social, é aquela que lhe dá o sentido de pertencimento e lhe permite reconhecer e exercer seu papel social ao constituir sua identidade profissional docente em interação com o outro, com e no contexto.

Esse caráter social da profissão permite ao professor desenvolver a noção de pertencimento a um grupo ou a uma categoria, quando em estágios mais adiantados de profissionalização. E essa noção de pertencimento é formadora da identidade, já que as relações estabelecidas constituem o terreno onde a autopercepção e a percepção que os outros têm do sujeito, através dos papéis exercidos, desenvolvem-se construindo identidades.

\section{Apresentação e análise dos dados}

As categorias inferidas a partir dos depoimentos dos professores revelaram marcadores identitários que, como símbolos culturais, segundo Veiga-Neto (2002), diferenciam e hierarquizam os indivíduos, contribuindo para o seu posicionamento. Assim, nesta seção apresentamos os marcadores identitários que nos foi possível identificar através da análise dos dados, usando como principal base de estudo o referencial teórico de Dubar (2005), já exposto em seção anterior. 
É importante destacar que, como a principal fonte de dados é constituída por depoimentos dos professores, a análise realizada contempla apenas a identidade para si (processo biográfico) descrito por Dubar (2005).

Os marcadores identificados são descritos em seguida e ilustrados com alguns depoimentos dos professores.

Condição de abandono: este marcador se relaciona com a forma como os professores se veem (identidade para si) após a repentina e inesperada saída das autoridades portuguesas para a ilha de Ataúro e sua retirada definitiva de Timor após a invasão indonésia. Foi devido a essa retirada que os timorenses se colocaram numa posição de "abandonados à própria sorte”.

Grupo A: Naquela altura os portugueses já abandonaram os timorenses e os timorenses substituiram os portugueses nos momentos mais difíceis. (José Silva).

Grupo B: A nossa população timorense, éramos num total de quinhentos e oitenta e oito mil nove centos e noventa habitantes, antes da saída incondicional dos Portugueses que deixou grande catástrofe, e abreviou o caminho para outro sofrimento do povo timorense, com a invasão de tropas indonésios de força bruta [...], com novos instrumentos de guerra para forçar-nos a serem indonésios: de certeza que não era fácil... Adormeceram-se mais de duzentas mil almas [...]. (Hélio).

Este marcador revela importantes atos de pertencimento, como, por exemplo, "ser um cidadão timorense" e "ser abandonado pelos portugueses", o que indica a aceitação da condição de povo submetido à dominação e ao sofrimento, embora com capacidade de luta e resistência, como veremos mais adiante na apresentação de outro marcador identitário.

Diplomacia: tem relação com a maneira diplomática dos timorenses enfrentarem uma situação de constrangimento na qual a sua sobrevivência estava em jogo.

Grupo B: O distrito de Oecusse é um dos Distritos muito diferente de outros doze. Seu sofrimento também foi diferente... Com a revolução de 25 de abril de $1974 \mathrm{em}$ Portugal deu caminho a autodeterminação de Timor. Era e foi verídico, Oecusse não sofreu bastante, mesmo durante a invasão da Indonesia, também não sofremos porque é um distrito que na geograficamente esta dentro do Coração da Indonesia, por isso temos que saber usar a diplomacia para sobreviver. (Claudio).

Grupo B: [...] e eu naquele momento (1999) ainda estive em Manufahi, decidi voltar para Baucau juntar com a família. Como não houve transporte eu com quatro colegas, decidimos de andar a pé de Manufahi para Baucau, que durou cinco dias de viagem e era uma viagem perigosa e cansativa, porque durante a viagem houve milícias que ameaçaram-nos para matar, foi bem dissemos que somos professores simples, por esse motivo que facilitamos a chegar até Baucau. (Filipe). 
Este marcador também mostra importantes atos de pertencimento: "sou um timorense que usa a diplomacia para sobreviver”. Essa característica, que parece incorporada à identidade do timorense, faz-se presente em momentos em que ele se vê às voltas com situações embaraçosas ou naquelas em que essa forma relacional pode ajudá-lo a garantir a sobrevivência.

As palavras de Hull (2001, p. 84) parecem vir ao encontro dessas nossas percepções que permitiram identificar um marcador identitário vinculado à diplomacia:

Aterrorizados com as represálias, os civis aprenderam a ser tímidos e circunspectos ao falar com o estrangeiro, mas ouvi algumas condenações surpreendentemente francas acerca da ocupação, vindas de indivíduos cuja confiança mereci, enquanto católico e falante de Tétum e Português.

Resiliência: refere-se à habilidade dos timorenses em resistir e sobreviver diante de adversidades. A sua extraordinária capacidade de resiliência é usada como modo de superação de situações de conflito, que podem ser vistas como oportunidades de transpor os próprios limites. Este marcador se revelou extremamente significativo, não apenas pela expressiva quantidade de depoimentos dos professores, como também pela diversidade de estratégias utilizadas para resistir ao invasor.

Grupo A: No ano de 1975 quando as tropas indonésias invadiram Timor-Leste as Forças Armadas da Libertação Nacional de Timor-Leste (FALINTIL) evacuaram para o mato e as montanhas. Naqueles tempos a maioria da população também evacuou para o mato incluindo o meu pessoal e a família. (Mario).

Grupo B: As forças da FALINTIL fizeram uma barreira a volta da população. $\mathrm{Na}$ medida que as forças da Indonesia iam apertar as forças da FALINTIL nós as populações tinhamos que evaquar outra vez de sítio. (João).

Grupo A: Eu e a minha família fugimos para o mato sob a proteção das forças FALINTIL, para podermos safar das mãos do inimigo. Não aguentei com a fuga de um local ao outro, então resolvi voltar à vila com a minha família. Também houve outras pessoas que voltaram à vila para que essas pessoas possam fazer ou colher informações para enviar aos outros que continuavam a resistir nas montanhas. (Telma).

Grupo A: Fomos pessoas e famílias nómadas desde o ano de 1976 a 1979. O percurso nomadez desse período foi de sofrimento nos contextos de habitação, comida, saúde, saniamento, tudo por motivos de perseguimento do ocupante. [...] Nunca permanecemos num lugar fixo. [...] Apenas dormimos debaixo de folhas verdes sobrepostas sem paredes. Casos apertados abrigámos dentro de cavernas, muitas vezes debaixo de copas das árvores, dormindo no chão apenas em cima de folhas também verdes estendidas, nada para cobrir o corpo, sofrendo assim o calor, o frio, a humidade, a chuva, o vento, o mosquito e todos os factores da natureza negativo à saúde. (Lourival). 
Nos depoimentos anteriores são relatadas experiências de sobrevivência associadas com a busca de refúgio nas montanhas e as estratégias utilizadas para garantir essa sobrevivência como forma de resistência à invasão.

Outras declarações dos professores revelam outras formas de resiliência: “Grupo B: Nos 24 anos de ocupação, estive no mato num período de 3 anos junto as Forças Armadas da Libertação Nacional de Timor-Leste (FALINTIL), contribuindo na luta contra os ocupantes defender a Independência do país" (Carlos). Este terceiro depoimento mostra um importante ato de pertencimento associado à resiliência: "sou um timorense em luta para garantir a independência".

Há ainda outros professores que resistiram utilizando mecanismos que garantiam certas continuidades, como a alfabetização na Língua Tétum. Observa-se, nesse caso, uma reprodução de identidades herdadas como mecanismo de sobrevivência.

Grupo A: Nos princípios do ano de 1976 até fim de 1978, estive no mato com outros patriotas fizemos a nossa resistência contra o invasor indonésio. Durante este período de resistência, fui professor de alfabetização nos princípios. Mas depois desviei-me para outras funções. (Júlio).

Já os professores mais jovens, os do Grupo C, ainda que não tenham vivenciado essa resistência e luta, narram esses fatos da forma em que eles os conseguiram subjetivar a partir de relatos de outros cidadãos mais velhos.

Grupo C: Na invasão da Indonésia a Timor-Leste no dia 7 de dezembro de 1975 eu ainda era pequenina não sabia nada sobre o que é que resistencia, mas a história foi contada pelo meu pai sobre a resistencia que passou na vila com a entrada dos indonésios fez com que toda a população se dispersavam para os sítios mais seguros para se defenderem dos bombardiamentos dos cainões e capturação para qual quer indivíduos para se abrigarem. [...]. (Gracia).

Esse depoimento nos permite inferir um processo de transição subjetiva entre uma identidade herdada - "sou um timorense em luta" - e uma identidade visada, a de ser uma cidadã timorense de um novo país, configurado após a retirada da Indonésia.

Criatividade: esta é uma marca do timorense que ao contar sua história exibe sua criatividade por meio de estratégias originais criadas em circunstâncias adversas para resolver problemas, especialmente visando à sobrevivência.

Muitos professores relatam como eles utilizaram seus conhecimentos em Botânica para identificar plantas com propriedades medicinais, por exemplo, e sobreviver em situações adversas. A 
maioria desses relatos é advinda dos professores mais velhos, do Grupo A, que eram adultos e tiveram de resistir à invasão.

Grupo A: Mas os que procuram sobreviver, interessaram em explorar folhas e cascas de plantas para fazer medicamentos, contra cólicas, malaria, tosse e feridas. Quanto à falta de comida procuravam adaptar com tudo o que se encontrava no mato para comer e viver. Foram explorando o feijão bravo, caules de palemiras produzido em sagú e alguns tuberculos feitos atravé de vários processos para não prejudicar o organismo. (Raquel).

Grupo A: Para as doenças como malária e diarreia curávamos com folhas de papaeira e goiabeira. (Moisés).

Também há relatos de descobertas muito criativas de "novos" alimentos devido à escassez de alimentos já conhecidos e à vida nômade que eles levavam.

Grupo A: Com o andar do tempo eu, os pais, os irmãos e as irmãs encontrámos muitas dificuldades principalmente na alimentação e saúde. A alimentação que levámos estando a acabar e não podemos trabalhar porque não tínhamos lugares fixos. Com esta situação, para manter a nossa vida temos que experimentar a comer os vegetais que nos rodeiam que nunca alimentámos na nossa vida. (Pedro).

Grupo B: Para sobreviver eles comiam kumbili de várias qualidades, maek, mandioca, frutos silvestres, todas as folhas que o cabrito come, eles comiam, como o ditado português: $O$ que não mata engorda. (Elsa).

Grupo A: Eu a família tivemos que experimentar a folha duma árvore chamada Aidak em língua Tetum. Em primeiro lugar cozémos as folhas do Aidak e depois de ser cozido, amassámos até que ficar sem água. Em seguida pomos o sal e misturámos com arroz ou mandioca cozida e consumimos. Foi a primeira vez que encorajei-me de comer esta folha. (Pedro).

Grupo A: [...] o resto do tronco e da raíz da palmeira, depois de uns tempos, aparecem umas larvas que contém muita gordura que são também para a alimentação. (Sonia).

Já os mais novos do Grupo C apenas relatam o que os mais velhos lhes disseram (identidades herdadas), como este trecho que narra as formas criativas de vestuário e de higienização do corpo:

Grupo C: Quanto ao vestuário usavam o pano dos para-quedas para defesa do organismo contra o frio e o calor. Para higiene do corpo e do vestuário usavam a casca de planta chamada kailoi, cinzas e folhas de fefe-leki [planta rastejante] em troca de sabão e omo. (Gracia). 
Aplicando as categorias de Dubar (2005), podemos inferir, a partir dos relatos, que há rupturas - "nunca antes se havia utilizado certas plantas e animais para alimentação" - e a produção de mecanismos de sobrevivência.

Disciplina: relaciona-se com o cumprimento ou acatamento às regras, ensinamentos e hábitos, em decorrência da herança de uma formação recebida desde o ensino básico, marcada por fortes condicionantes religiosos, linguísticos e por um ensino tradicional.

Grupo B: A formação que recebi desde a escola primária até ao pré-secundário foi uma educação tradicional e agressiva. O processo de aprendizagem era concentrada no professor e o aluno aprendia as lições não pela livre vontade mas sim pelo medo devido da agressividade do professor. [...] copiavam as lições no quadro e obrigavamnos a decorar as lições como se fosse orações. [...] por outro lado com o método agressivo resultou boa qualidade na formação intelectual, moral e religiosa. (Amaro; grifo nosso).

Grupo A: [...] O meu professor era um catequista já bastante velho. [...]. Todos os alunos eram obrigados a levar lenha, água para atender as necessidades do professor. As aulas são realizadas na parte de manhã e a tarde, os alunos são obrigados a trabalhar na horta do professor durante um determinado tempo antes de regressarem para as suas casas. (Juvenal).

Alguns outros relatos revelam um grande esforço no deslocamento até a escola, condições precárias de infraestrutura escolar, ou, inclusive, dificuldades de ordem financeira e familiar, que exigiam uma forte disciplina para concluir os estudos.

Grupo A: Em 2004 o Ministério da Educação mandou um mandato para todos os professores de frequentarem o Pré-bacharelato no distrito de Aileu, para lá me deslocava todos os dias. Foram três anos de dificuldades e de trabalho intenso. Depois lá consegui acabar o curso de Bacharelato em 2007. (Carmem).

Grupo C: Na minha vida durante na escola tivera muitas dificuldades e nesecidades. $O$ meu pai não trabalha no momento e a minha mãe é mesma. Os meus pais so agricultura, trabalharam na vida de agricultura. [...]. Mesmo assim dia-a-dia não desanimaram, mas tentamos procurar a outra maneira para sustentarem a nossa família. (Lourdes).

Grupo B: E essa escola nas áreas rurais construido pelo capim e os bancos, as mesas construido pelo bambo. [...]. Entretanto não havia nada uma casa para morar e a distância de Atsabe para essa escola por volta de $5 \mathrm{~km}$, então ida e volta durante 2 (dois) anos [...]. (José Luís).

Grupo A: [...] Aí fiz a dupla função [1974]: dava aulas de manhã e à tarde ia à escola. Com essa maneira consegui acabar o ensino secundário. (Ana). 
Observa-se, nos depoimentos, a presença de marcadores identitários herdados, que indicam continuidades e reprodução, como a Língua Indonésia (no período da dominação) e o ensino tradicional marcado pela reprodução e pelo foco na figura do professor.

Esses marcadores herdados condicionam fortemente a prática dos professores timorenses, ainda que essa prática não seja objeto de estudo deste trabalho.

Vocação para o desvelo e para o ensino: representa uma característica bastante comum entre os timorenses relacionada ao cuidar por meio de atividades educativas, quaisquer que sejam estas. Em vários relatos, os professores narram experiências de voluntariado relacionadas à alfabetização ou ao ensino de modo mais geral. Inclusive, vários deles expressam que essas experiências foram desenvolvidas por um "chamado" a ajudar o próximo, relacionado ao desvelo.

Grupo A: Depois da consulta popular continuei a estabelecer as actividades na escola primária até o ano 2000 como professora voluntária. Candidatei novamente para professora permanente no serviço da UNTAET. (Ana Belo).

Grupo C: [...] o padre Eligio Locatelli da congregação salesiana em Fatumaca pediume (1990) para ensinar na escola primária católica Uailili e acetei este pedido e trabalhei durante um ano de ser professora nesta escola (professora que ainda não entender melhor esta profissão). Uma fase importante na minha vida de ser professora encontrei no Instituto, comecei saber e entender detalhadamente sobre a minha vocação foi uma chamada para transmitir a educação na escola e na comunidade. (Gracia)

Grupo A: [...] a situação de Timor já estava quase grave [1975]. Então fiz uma pausa [...]. Eu e a minha família fugimos para o mato, durante 3 anos. [...] lá, via que tinha muitas crianças, jovens e adultos e que eles não faziam nada resolvi experimentar o ensino aprendizagem da alfabetização [...]. E dentro da memória ia pensando que era bom seria uma educadora. (Glória).

Grupo A: Lá no mato durante a vida da resistência [1975 a 1979], dava aulas de alfabetização para os adultos. Também eu ia sempre acompanhar os enfermeiros, fazer tratamentos aos doentes e aos soldados feridos atingidas pelas balas dos inimigos, com os remédios tradicionais as quais são as folhas e raízes das plantas. (Ana).

Grupo B: [...] e naquele momento [1987] fomos a trabalhar como os professores do ensino primário, sem salário durante 4 (quatro meses), mas era normal porque amavamos as nossas profissões como professores [...]. (José Luís).

O altruísmo no exercício dessa vocação contribui, na visão desses professores, para o progresso do país e consequente melhoria na condição de vida das pessoas. 
Grupo B: [...] quando frequentei a escola secundária observei que não havia nenhum professor timorense. Todos eram indonésios e aproveitaram a oportunidade de manipular e politizar os jovens a desconhecer o seu país e a sua própria cultura. Com essa situação sinto-me chamado pela voz da minha consciência e o rumor da voz do meu coração, tenho que inserir-me dentro do processo de formação dos jovens timorenses na escola. (Amaro).

Esses depoimentos mostram um importante ato de pertencimento: "Sou um professor que ama sua profissão". E uma identidade herdada de gerações anteriores, vinculada à ideia de que o professor tem que ter "vocação" ou uma "missão".

Religiosidade: a legitimidade e o poder conquistados pela Igreja Católica, principalmente nos anos de domínio indonésio, ficam evidentes nos relatos dos professores e revelam uma importante marca que tem contribuído na construção identitária do seu povo que, majoritariamente, declara-se católico, apesar do viés animista presente em algumas práticas e rituais.

Grupo C: Quando cheguei naquela escola [1991] fiquei muito admirável porque tinham lição e materiais novas e também professores que ensinavam nesta escola foram os indonésios a exepção dos professores timorense que ensinavam só lições religião e língua inglesa. (Antonio).

Grupo C: [...] Em seguida tive a oportunidade de continuar a minha formação no Seminário de Nossa Senhora de Fátima llaxante-Dili durante três anos. Nesta formação, na parte da manhã, frequentava as aulas de formação espiritual e língua portuguesa. Na parte de tarde participava nas aulas da Escola Secundária Católica de S. José em língua indonésia. (Amaro).

Na narrativa anterior, do professor Amaro, percebe-se que, apesar do domínio indonésio e dos rigores no combate à Língua Portuguesa, o seu ensino ainda era verificado. Isso somente era possível por se tratarem de escolas administradas pela Igreja. Como afirma Bolina (2005, p. 184):

No longo e conturbado processo de luta contra o país invasor, a Indonésia, país maioritariamente muçulmano, e a correspondente tentativa de neocolonialismo por parte deste, a Igreja Católica assumiu sempre um papel decisivo na defesa e preservação da cultura e identidade de Timor, nomeadamente ao traduzir a liturgia em Tétum, a língua predominante de Timor.

Em defesa da tradicional sociedade timorense, Hull (2001) considera que, naquele contexto, há elementos do passado que são reconhecidos como essenciais pelo povo e outros não. O catolicismo e o uso da Língua Portuguesa fazem parte da primeira categoria, ou seja, seguir a religião católica, apesar de marcantes traços animistas presentes em algumas práticas, é bastante comum entre os timorenses. Já, a poligamia, as guerras entre as tribos, o uso do malaio e a caça às cabeças pertencem à segunda. 
A presença da Igreja Católica também se evidencia na formação recebida no ensino médio e superior, inclusive no Bacharelato.

Grupo B: Depois de ter suspendido durante dois anos, por fim continuei novamente a minha formação na escola superior (Instituto de Ciências Religiosas) em Dili durante três anos. Nesta formação aprofundei bastante o meu conhecimento especialmente na área da educação e formação de jovens. Finalizei os meus estudos com uma graduação perante o Bispo da Diocese de Dili Mgn. D. Filipe Ximenes Belo, SDB, no fim de 1990. (Amaro).

Grupo C: Um ano seguinte em 1991, através do padre Eligio Locatelli SDB, continuei o meu estudo no SCR: Instituto Ciência Religiosa, naquele momento foi chamado de IPI: Instituto Pastoral Indonésia, filial Malang Indonésia em Dili, e ele pagou o meu estudo até terminei. (Gracia).

Grupo A: Em 1993 foi chamada pelo Instituto Pastoral Indonesia (IPI) para formação específico como o curso de Bacharelato, para ter diploma II. No fim terminava no ano de 1997. Recebi a graduação no dia 27-6-1997 em Díli. (Bárbara).

Esses depoimentos deixam transparecer o papel exercido pela Igreja Católica durante o período da invasão indonésia e sua particular e efetiva forma de ajudar a população, preservando a cultura e identidade timorenses. Nesse sentido, a Igreja é tomada como uma instituição atraente ou protetora com a qual as pessoas se identificam, como explicitado por Dubar (2005).

\section{Considerações finais}

Esta pesquisa foi desenvolvida a partir dos cursos de formação inicial e continuada implementados em Timor-Leste com a participação da cooperação brasileira e que estão inseridos no âmbito do ensino de Biologia, buscando fornecer subsídios referentes às metodologias necessárias ao desenvolvimento de competências pedagógicas que conduzam ao sucesso na aprendizagem das crianças e dos jovens timorenses, agora em Língua Portuguesa.

Ao considerar o processo reflexivo que a formação de professores pode promover e a ressignificação da profissão que daí advém, almejou-se, levando em conta as suas limitações, incitar debates sobre como o professor daquele país que ensina Biologia tem estabelecido a construção da sua identidade profissional e em que medida esse reconhecer-se (e ser reconhecido) professor exerce influência sobre a sua docência. 
Um importante aspecto a se considerar no trabalho de formação docente é o conhecimento e consequente respeito à cultura local, pois o ensino pode ser desenvolvido com fluidez e a aprendizagem se dá de forma significativa. Considera-se que os professores timorenses devem ser os protagonistas da sua própria aprendizagem, visto que suas características e seus anseios docentes estariam sendo reconhecidos e considerados no planejamento das ações educativas dos formadores. Nesse sentido, o conhecimento do processo de construção identitária desses professores se torna fundamental para promover ações de formação continuada que levem em consideração quem é esse sujeito professor que participa dos cursos de formação.

As identidades profissionais de professores, assim como as de outras categorias profissionais, constituem-se dentro de uma cultura profissional partilhada, que tem seus modos próprios de agir com base em normas e valores característicos da profissão docente (DUBAR, 2005). No entanto, essas identidades profissionais pressupõem uma socialização específica que não se dá independentemente de outras socializações. Assim, há um claro caminho percorrido pelos professores até a construção da sua identidade profissional que é moldado ao longo do tempo e se assenta nas experiências vividas ou percebidas. O que ficou bastante aparente em nossa pesquisa é que os timorenses que ensinam ou ensinarão Biologia requerem um tempo de vivência na prática para constituirem suas identidades profissionais, partilhando uma cultura profissional.

A análise dos dados coletados aponta coerências com a hipótese que deu início ao desenvolvimento da pesquisa, isto é, os processos que estão envolvidos na construção da identidade do professor leste-timorense que ensina ou ensinará Biologia estão relacionados ao contexto histórico, político e cultural de Timor, visto que os marcadores identitários que incidem sobre essa construção têm sido forjados na e pela sua história. Declaradamente, há nos documentos coletados referências que conduzem a alguns marcadores identitários clássicos, como, por exemplo, a religiosidade e a disciplina, que especificamente em Timor-Leste aparecem imbricados noutros bem particulares àquele contexto e que estão transitando na profissão de professor ou de professor que ensina Biologia, como a vocação para o desvelo e para o ensino, a resiliência, a diplomacia, entre outros.

Logicamente que este estudo não teve a pretensão inicial de estabelecer relações entre marcadores identitários, muito menos relações de natureza causal, inclusive porque os dados não possibilitaram conexões tão fortes. Mas, partindo da análise realizada e dos marcadores identitários 
identificados, é possível conjecturar que tais marcadores parecem formar um entrelaçamento, pois há indícios de algumas associações entre eles, como argumentamos a seguir.

A condição de abandono parece estar vinculada à resiliência, ou seja, a capacidade de sobreviver e resistir em condições adversas decorrentes da invasão indonésia e do jugo a que foram submetidos. Por sua vez, essa resiliência aparece associada à diplomacia, que se expressa em situações onde a sobrevivência está em jogo, e à criatividade, manifesta pela forma na qual os professores utilizavam de seus conhecimentos para identificar plantas medicinais ou comestíveis e superar doenças ou fome. Por outro lado, os marcadores disciplina e resiliência aparecem juntos, na medida em que para resistir, é importante ser disciplinado, seguir regras e se esforçar para o benefício da comunidade. Também, os professores timorenses desenvolveram uma vocação para o desvelo e para o ensino, que se manifesta em situações nas quais a sobrevivência está sendo colocada à prova, seja sobrevivência no sentido físico do termo, de cuidado e preservação da vida, ou sobrevivência da identidade timorense, pela continuidade nos ensinamentos, por um "chamado" a servir ao próximo em situações adversas ou com carências educacionais. Finalmente, a religiosidade atravessa vários dos outros marcadores no sentido de dar continuidade a uma identidade herdada da tradição portuguesa e que aparece associada à disciplina e à vocação para o desvelo e o ensino, pela preservação de práticas, rituais e alguns elementos do passado, como forma de resiliência à dominação indonésia.

Assim, a argumentação anterior nos leva a induzir que se há um elemento estruturante nas identidades dos professores timorenses, poderíamos dizer que é a resiliência, que ficou evidente nas circunstâncias histórico-políticas que eles atravessaram e em torno da qual os demais marcadores parecem se manifestar.

Com relação à Missão de Cooperação Internacional, considera-se que, naquela época da formação continuada, um pequeno passo foi dado. No entanto, na saída do país se via com clareza que bem mais do que foi realizado ainda estava por fazer. Fato é que os programas ainda continuam sendo promovidos pela Capes em território timorense com a coordenação acadêmica da Universidade Federal de Santa Catarina (UFSC) e com significativas melhorias. Os dados ora analisados apontam as carências, dificuldades e, principalmente, as necessidades do professor que leciona ou pretende lecionar a disciplina de Biologia para as crianças e jovens timorenses. Isso, por si só, já sinaliza as metas a serem perseguidas futuramente, e, dentre elas, considera-se a participação do timorense no papel de professor formador uma das mais importantes a ser alcançada. 
Ao cooperante é imperioso observar a necessidade de conhecimentos, ao menos elementares, da Língua Tétum como forma de compreensão das suas semelhanças e diferenças em relação à Língua Portuguesa, sendo fundamental o respeito às marcas identitárias.

\section{REFERÊNCIAS}

BOLINA, Mariette. Timor e a Língua Portuguesa no seu Projecto Educativo. Revista Lusófona de Educação, Lisboa, n. 6, p. 179-193, 2005.

BRASIL. Ministério das Relações Exteriores. Protocolo de Cooperação Técnica entre o Governo da República Federativa do Brasil e a Administração Transitória das Nações Unidas em Timor-Leste, fundado no Acordo de Cooperação Brasil - ONU. Brasília, 22 jul. 2000. Disponível em: <http://daimre.serpro.gov.br/atos-internacionais/bilaterais/2000/b_58/at_download/arquivo>. Acesso em: 23 mar. 2016.

BRASIL. Ministério das Relações Exteriores. Cooperação Brasil-Timor-Leste. Agência Brasileira de Cooperação, Brasília, 2012. Disponível em:

<http://www.abc.gov.br/Projetos/CooperacaoSulSul/TimorLeste>. Acesso em: 2 jun. 2015.

BRASIL. Decreto $n^{\circ}$ 5.274, de 18 de novembro de 2004. Institui o Programa de Qualificação de Docente e Ensino de Língua Portuguesa no Timor-Leste, e dá outras providencias. Diário Oficial da União, Brasília, DF, 19 nov. 2004. Disponível em: <http://www.planalto.gov.br/ccivil_03/_ato20042006/2004/decreto/d5274.htm>. Acesso em: 23 mar. 2016.

CHAMON, Edna Maria Querido de Oliveira. Formação e (Re)construção Identitária: Estudos de Memórias de Professores do Ensino Básico Inscritos em Programa de Formação Continuada. 2003. 117 f. Tese (Doutorado em Educação) - Universidade Estadual de Campinas, Campinas, SP, 2003.

DUBAR, Claude. A socialização: construção das identidades sociais e profissionais. São Paulo: Martins Fontes, 2005.

GERTIL. Grupo de Estudos de Reconstrução de Timor-Leste. Atlas de Timor-Leste. Lisboa: LIDEL; Edições Técnicas, 2002.

HULL, Geoffrey. Timor-Leste: identidade, língua e política educacional. Lisboa: Instituto Camões, 2001.

VEIGA-NETO, Alfredo. As idades do corpo (material)idades, (divers)idades, (corporal)idades, (ident)idades. In: GARCIA, Regina Leite (Org.) O corpo que fala dentro e fora da escola. Rio de Janeiro: DP\&A, 2002. p. 35-64.

VIANNA, Claudia. Os nós do "nós": crise e perspectiva da ação coletiva docente em São Paulo. São Paulo: Xamã, 1999. 
Identity Markers of Biology teachers from East Timor: a study derived from an experience in international cooperation

\begin{abstract}
Living and working with the Mission for Cooperation between Brazil and East Timor from 2007 to 2009 were the reasons for this study focused on the constitution of the teaching identity of Biology teachers in that country and its close relationship with the political, historical, social and cultural contexts of East Timor. This study aimed to investigate the identity markers of East Timorese teachers reportedly present in that period, which have possibly conditioned the construction of the professional identity of these Biology teachers. The research sought to answer questions such as: How, in the face of the Timorese scenario, has the (re)construction of the professional identity of the teachers who teach biology been happening? Or which identity markers affect the configuration of these identities? The research was theoretically grounded in the concepts of Claude Dubar on the formation of social identities. The methodology is anchored in bibliographical and documentary research, through the interpretation and analysis of documentary records and memorials collected during the training undergone during an international cooperation project. In the data analysis it was observed that the identity markers of these teachers show influences stemmed from their recent history of domination and freedom, survival and resistance.
\end{abstract}

Keywords: Professional Identity. East Timor. Teachers on-service Training.

\section{Marina Pereira Reis}

E-mail: marina-reis@usp.br

Verónica Marcela Guridi

E-mail: veguridi@usp.br

Elisabeth Barolli

E-mail: ebarolli@unicamp.br
Marcadores de Identidad del profesor de Biología de Timor Oriental: un estudio a partir de una experiencia de cooperación internacional

\section{Resumen}

La convivencia y el trabajo en la Misión de Cooperación entre Brasil y Timor Oriental en el período de 2007 a 2009 fueron las razones para realizar este estudio sobre la constitución de la identidad docente del profesor de Biología de este país y su estrecha relación con el contexto político, histórico, social y cultural del territorio timorense. Este trabajo busca investigar las marcas de identidad del profesor timorense declaradamente presentes en el período, que posiblemente han condicionado la construcción de la identidad profesional de esos docentes de Biología. La investigación buscó responder a los siguientes interrogantes: ¿Cómo se ha dado la (re)construcción de la identidad profesional de los docentes que enseñan Biología en el escenario timorense oriental? O también, ¿cuáles son las marcas de identidad que inciden en la configuración de esas identidades? La investigación se apoyó teóricamente en las conceptuaciones de Claude Dubar a respecto de la constitución de las identidades. La metodología utilizada estuvo basada en la investigación bibliográfica y documental, por medio de la interpretación y análisis de registros documentales y memoriales colectados durante la formación realizada en un proyecto de cooperación internacional. En el análisis, fue posible observar que las marcas de identidad de esos profesores evidencian influencias oriundas de su reciente historia de dominación y libertad, sobrevivencia y resistencia.

Palabras claves: Construcción de la identidad. Timor Oriental. Formación de Professores.

Enviado em: 20/5/2015

Aprovado em: 14/11/2015 